MATEC Web of Conferences 9, 02003 (2013)

DOI: $10.1051 /$ matecconf/20130902003

(C) Owned by the authors, published by EDP Sciences, 2013

\title{
Façade fire tests - measurements and modeling
}

\author{
Johan Anderson and Robert Jansson
}

\author{
SP Technical Research Institute of Sweden, Borås, Sweden
}

\begin{abstract}
In two recent papers [1,2] the fire dynamics in a test rig for façade constructions according to the test method SP Brand $105[3,4]$ was investigated both experimentally and numerically. The experimental setup simulates a three-story apartment building (height $6.7 \mathrm{~m}$, width $4 \mathrm{~m}$ and depth $1.6 \mathrm{~m}$ ), with external wall-cladding and a "room fire" at the base. The numerical model was developed in the CFD program Fire Dynamics Simulator (FDS) [5] with analogous geometry and instrumentation. The general features of the fire test were well reproduced in the numerical model however temperatures close to the fire source could not be properly accounted for in the model. In this paper the bi-directional probe measurements are elaborated on and the test used in Ref. [1] is revisited using different heat release rates in the numerical model. The velocity of the hot gases along the façade was well reproduced by the simulations although some deviations were found.
\end{abstract}

\section{INTRODUCTION}

A variety of different test methods have been proposed in order to evaluate fire spreading from floor to floor via external walls for different wall claddings, insulations and geometries [3]. The SP Fire 105 test method for façade systems was defined in 1985 [4] and simulates a three-story apartment building, height $6.7 \mathrm{~m}$, width $4 \mathrm{~m}$ and depth $1.6 \mathrm{~m}$, shown in Figure 1 and Figure 2 . The experimental setup is intended for determining the fire behavior of external wall assemblies and façade claddings, exposed to heat and flames coming out from an opening in a room with a fully developed apartment fire. The test is designed to evaluate external fire spread on the surface, internal fire spread in enclosed burnable components in the system, as well as recording falling down of parts including the occurrence of burning droplets.

The fire source is a tray (width $\times$ length $\times$ height: $500 \mathrm{~mm} \times 2000 \mathrm{~mm} \times 100 \mathrm{~mm}$ ) filled with 60 liters of heptane with a free-board of water below to ensure an even level at the base of the tray and facilitate burning across the full width of the tray throughout the test. The burning of 60 liters of heptane with a combustion efficiency of 0.8 corresponds to a fire load of approximately $75 \mathrm{MJ} / \mathrm{m}^{2}$ total fire room surface. In order to create a more stable flame, a flame suppressing lattice consisting of a perforated steel sheet with pipes of $25 \mathrm{~mm}$ diameter is placed on the fire tray, shown in Figure 3. This method has then been presented internationally for different standardization committees. It has been classified as a valid test method in Sweden, Denmark and Norway although it is not a European standard. In the standard fire test two thermocouples are placed under an eave, six meters above the fire room and a heat flux meter is placed in a lower fictitious window 2.1 meter above the fire room.

In two recent papers [1,2] the fire dynamics was investigated in the SP Brand 105 test rig both experimentally and numerically. The numerical model was constructed in the CFD program Fire Dynamics Simulator (FDS) version 5.5.3 [5] with analogous geometry and instrumentation.

In the previous work, the whole scenario during fire exposure was modeled and additional measurements conducted during several experimental fire tests were used for comparison with the simulations. A good correspondence could be found between the shielded thermocouples in the FDS model compared with an experiment in the SP Fire 105 test rig. Although a simplified model of the

This is an Open Access article distributed under the terms of the Creative Commons Attribution License 2.0, which permits unrestricted use, distribution, and reproduction in any medium, provided the original work is properly cited. 
MATEC Web of Conferences

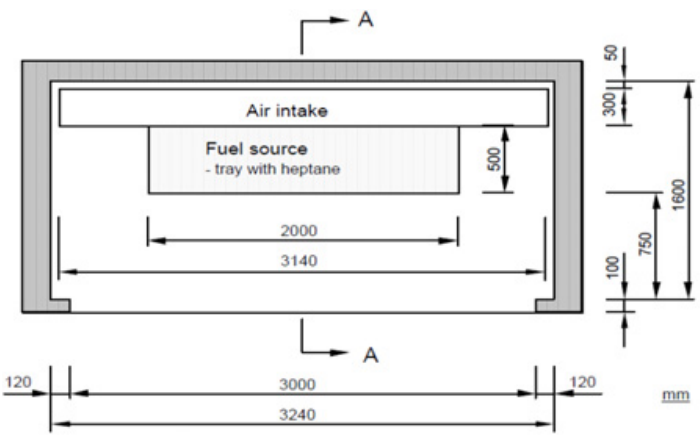

Planview of fire room

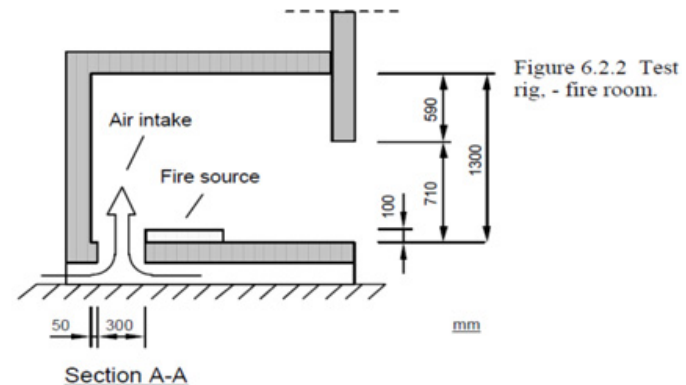

Figure 1. The spatial dimensions of the fire room from SP Fire 105 [4].

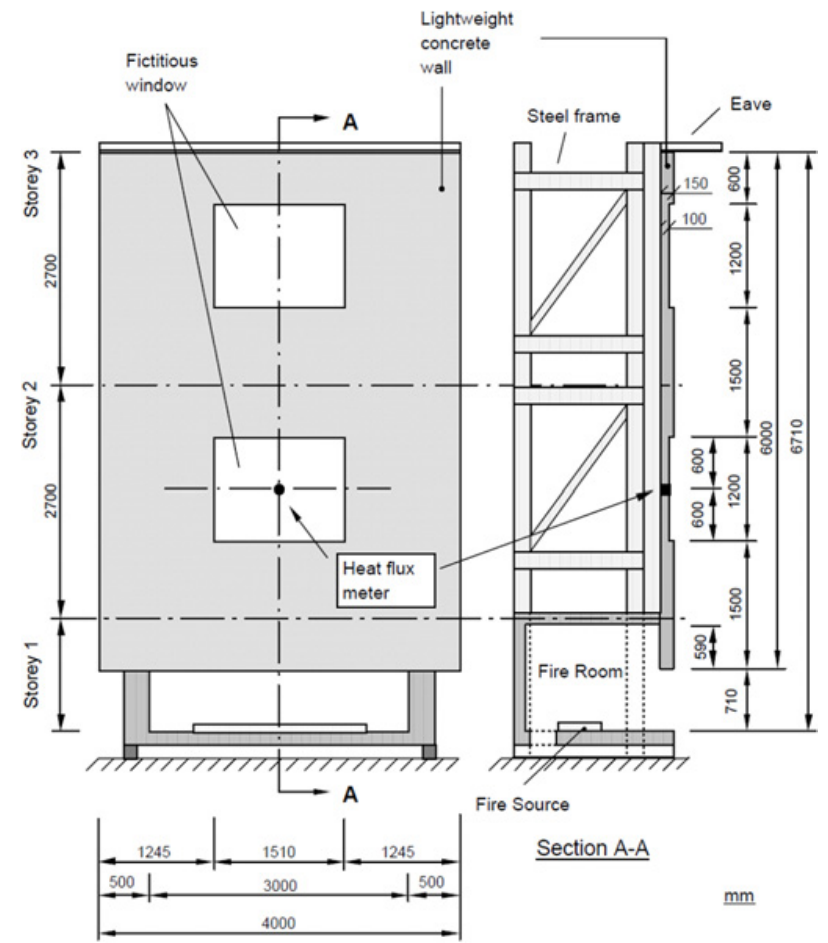

Figure 2. The façade front and side with spatial dimensions are shown from SP Fire 105 [4]. 


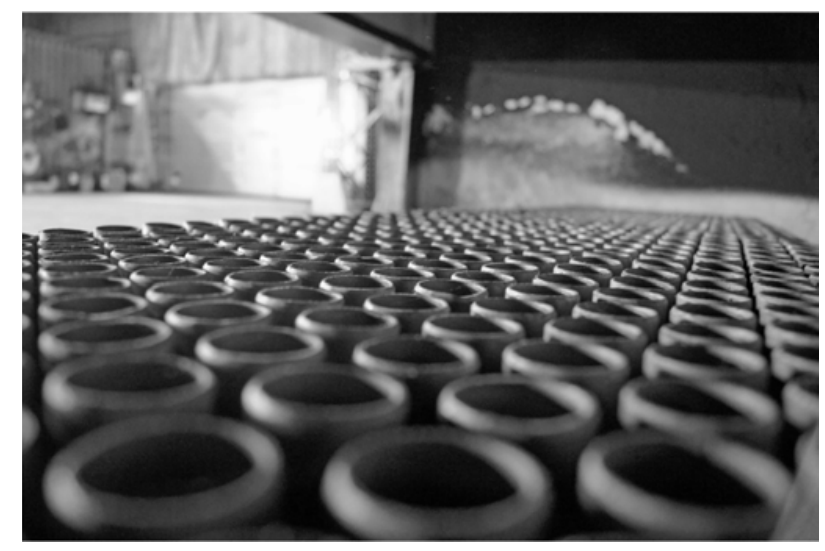

Figure 3. The flame suppressing lattice consisting of a perforated steel sheet with pipes of $25 \mathrm{~mm}$ diameter is placed on the fire tray.

fire tray was employed the calculated values for thermocouples correspond well with the measurements. The same correspondence was not found for the plate thermometers close to the burning chamber. For these cases the model gave substantially higher temperatures. Reasons for this are unclear however it is expected that the shape of the flame suppressing lattice in the fire tray that lead to different local radiation effects compared to burning from a liquid surface.

In the present work, we report on more fire tests and further development of the numerical model where new more accurate measurement of the heat release rate from a fire test with an inert wall assembly has been used as an input parameter in the numerical model. This is done as it is very difficult to model the flame suppressing lattice in the fire tray. Furthermore, we investigate the flow speed along the façade measured by bidirectional probes [7]. The mathematical procedure for converting the measured pressure differences in the bidirectional probes to flow velocities from Ref. [8] was used.

\section{EXPERIMENTAL SETUP}

The experimental setup described in the SP Fire 105 [4] is intended for determining the fire behaviour of external wall assemblies and façade claddings, exposed to heat and flames from an apartment fire. After fire exposure the construction, typically a combustible inner core protected by plaster, is cut into pieces to assess the internal fire spread in the core. Standard measurements during tests are heat flux to the centre of the lower fictitious window and two temperatures $100 \mathrm{~mm}$ under the eave, 100 and $400 \mathrm{~mm}$ from the façade measured by $0.25 \mathrm{~mm}$ thermocouples.

\section{MODELING}

The numerical work was performed using Fire Dynamics Simulation (FDS) version 5.5.3 [5]. The Navier-Stokes equations in the limit of low-speed, thermally-driven flow with an emphasis on smoke and heat transport from fires are solved by the FDS software. The algorithm used is an explicit predictorcorrector scheme that is second order accurate in space and time where turbulence is treated by means of Large Eddy Simulation (LES) in the Smagorinsky form. This is in contrast to other CFD codes for fire safety engineering where Reynolds averaged Navier-Stokes models are used. The heat transfer by radiation is included in the model via the solution of the radiation transport equation for a gray gas. The equation is solved using a finite volume technique for convective transport, thus the name given to it is the Finite Volume Method (FVM). When using 100 discrete angles are used for the radiation calculation, 
Table 1. Tests modelled.

\begin{tabular}{|c|c|c|c|}
\hline & $\begin{array}{l}\text { HRR in } \\
\text { numerical model }\end{array}$ & Instrumentation & $\begin{array}{l}\text { Thermal properties of } \\
\text { façade surface material }\end{array}$ \\
\hline Test A & Shown in Figure 4. & $\begin{array}{l}\text { Plate thermometers, thermocouples and } \\
\text { differential pressure probes in the two } \\
\text { fictitious windows }\end{array}$ & Ref. [9] \\
\hline Test B & Shown in Figure 4. & $\begin{array}{l}\text { Plate thermometers, thermocouples and } \\
\text { differential pressure probes at several } \\
\text { different positions. }\end{array}$ & From measurements \\
\hline
\end{tabular}

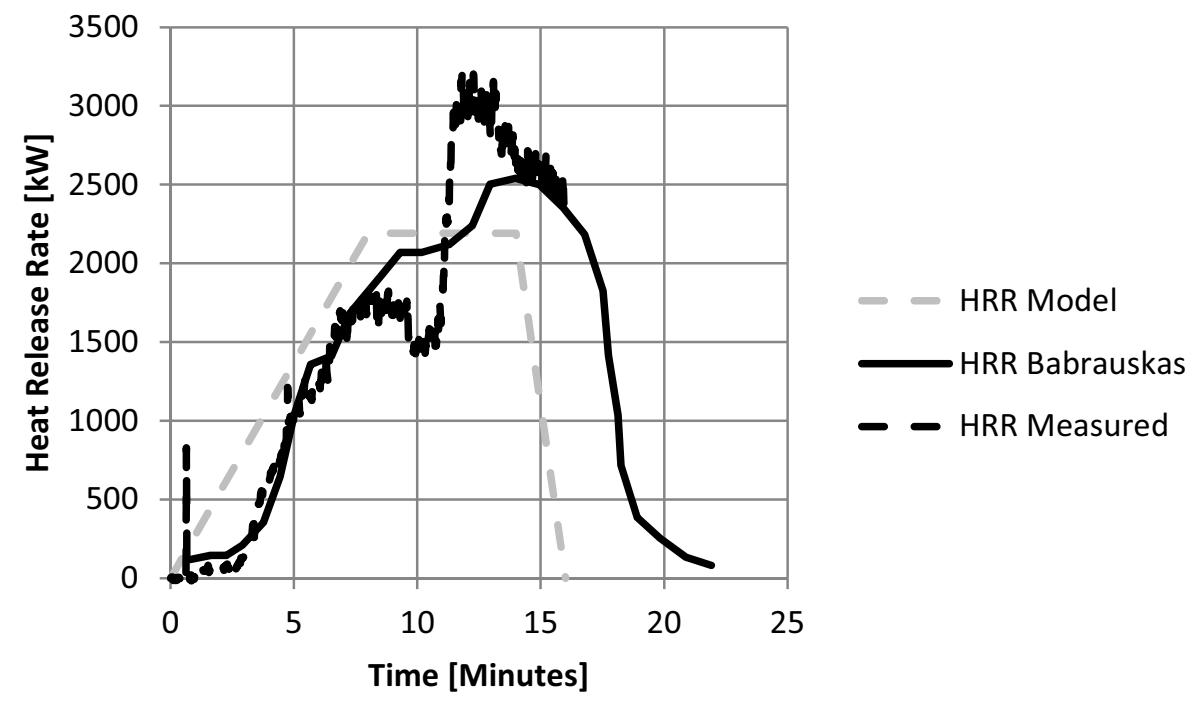

Figure 4. In the simulations three different estimated heat release rates from fire tray are used that will be used to analyze test $\mathrm{A}$ and $\mathrm{B}$.

the finite volume solver requires about $20 \%$ of the total CPU time of a calculation, a modest cost given the complexity of radiation heat transfer. In all further simulations a grid size of $5 \mathrm{~cm}$ cubes will be used. In [1], a grid sensitivity study was made and it was deemed that a $5 \mathrm{~cm}$ grid was sufficient to reproduce most of the relevant features.

\section{COMPARISON BETWEEN EXPERIMENTAL AND NUMERICAL RESULTS}

In this section we will elucidate on the measurements of gas velocity by the bi-directional probes and the effects of heat release rates in the simulations. To this end we will use measurement data from two different experiments (called Test A and B) and analogous modeling, test matrix shown in Table 1.

The first test, test A, was performed with extra instrumentation in front of the fire room as well as in the air intake behind the fire tray and the second test, test B, was equipped with extra instrumentation in the upper and lower fictitious windows. In addition, we have as a reference used a measured heat release rate from an inert wall shown in Figure 4.

Due to the complexity of the geometry of the fire source, in particular the fire tray made of perforated steel sheet; detailed modeling of evaporation of the fuel due to back radiation and subsequent combustion is difficult to manage in the models. As the weight loss of the fuel was not recorded during the first test an estimation of the heat release rate was made, in Test A. Visual observation during the 

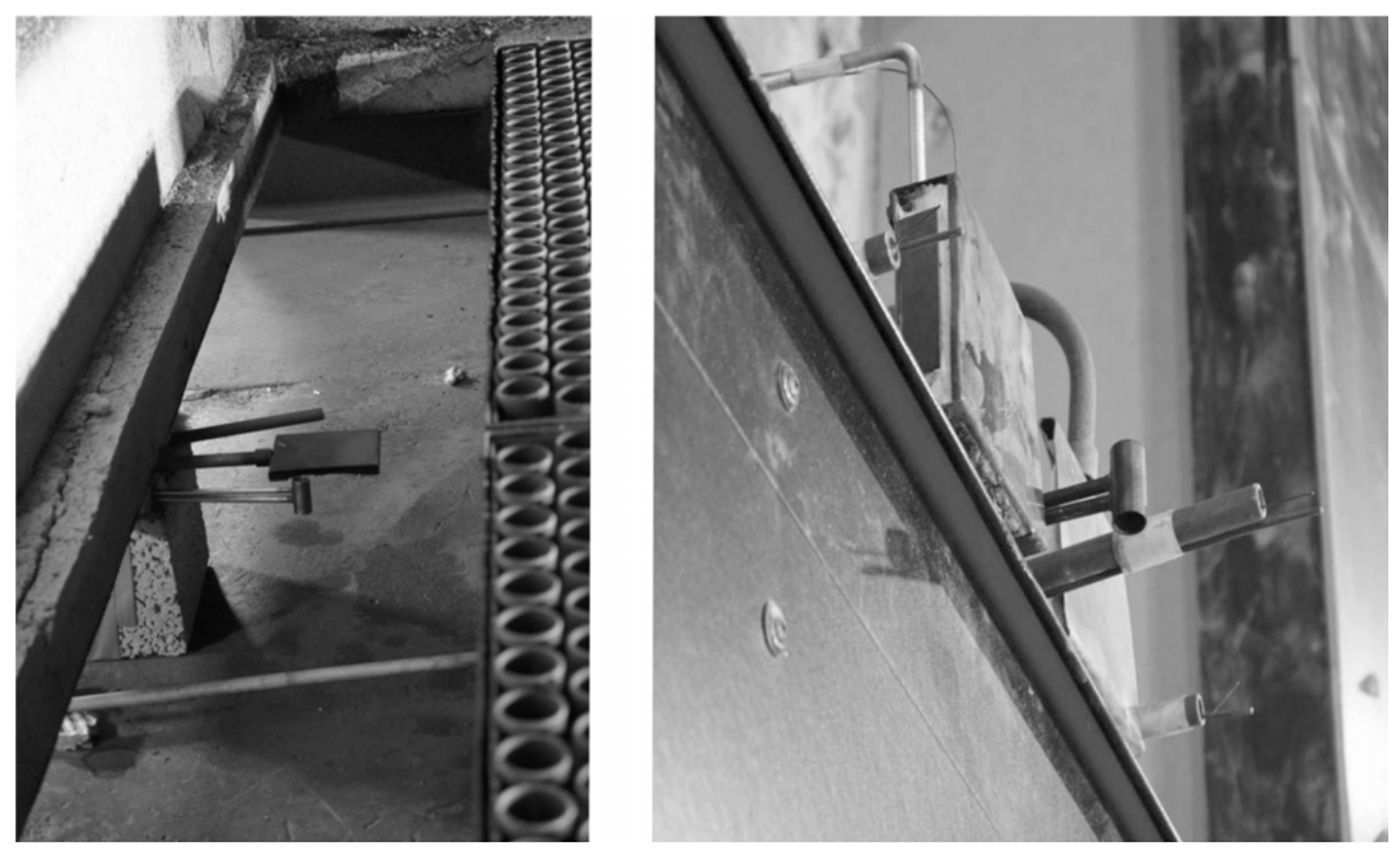

Figure 5. a) The measurement stations in the air-intake (Test A). b) The measurement stations at the lower edge of the window (Test B).

fire test showed a clear highest level of fire intensity between 8 to 14 minutes and that the fuel was consumed after approximately 16 minutes, the curve shown in Figure 5 was defined, for test A. This can be compared with values previously measured by Babrauskas by using the large scale products calorimeter at SP during four SP Fire 105 tests published previously [6]. The average value from these four tests is included in Figure 4. As seen in the figure the area under the mean of the measured [6] curves is larger than under the estimated curve. The reason is that the burning of the tested insulation systems on the façades is included during a measurement with the large scale industrial calorimeter. A rough estimation of the energy in the damaged areas reported by Babrauskas shows approximately $5-10 \%$ extra energy from the burning of the insulation materials which corresponds fairly well with the difference in area under our estimation and area under the curve from the previous measurements.

During test B, shown as "HRR Measured" in Figure 4, a small peak in HRR was observed in the early stages of the test followed by a shorter colder period commenced followed by the full force of the fire until the fuel was bunt away. Comparing with the previously defined HRR this does not include this pulsating feature of the fire in this particular test. Nevertheless, useful information could be obtained from studying such a case with this simplified model. In an earlier paper [1] very good correspondence between the test results and the simulations were achieved for the thermocouples whereas some of the plate thermometers where far off, in particular the temperatures measured at short distance from the fire source. The material data of the wall-cladding in Table 2 for test B is found by measurements of the thermal conductivity and the heat capacity utilizing the Transient Plane Source (TPS) method.

\section{VELOCITY MEASUREMENTS USING BD-PROBES}

The velocities of the hot gases in the air intake and along the façade by the use of bi-directional probes (BD-probes) [7, 8], were estimated in test A and B, respectively. The BD-probes are placed in the airintake and symmetrically, test A at the lower edge of the lower and upper window, test B, see Figure 5. 
Table 2. Material data used in the numerical analysis. The Siporex data is found in Ref. [9] whereas the data for the wall-cladding in test $\mathrm{B}$ is found by measurements.

\begin{tabular}{|l|l|l|l|}
\hline Material $\backslash$ Property & Density $\left(\mathrm{kg} / \mathrm{m}^{3}\right)$ & $\begin{array}{l}\text { Heat conductivity } \\
(\mathrm{W} / \mathrm{m} \mathrm{K})\end{array}$ & $\begin{array}{l}\text { Heat capacity } \\
(\mathrm{kJ} / \mathrm{kg} \mathrm{K})\end{array}$ \\
\hline Siporex (Test A) & 500 & 0.15 & 1.000 \\
\hline $\begin{array}{l}\text { Wall-cladding } \\
\text { (Test B) }\end{array}$ & 1115 & 0.199 & 0.793 \\
\hline
\end{tabular}

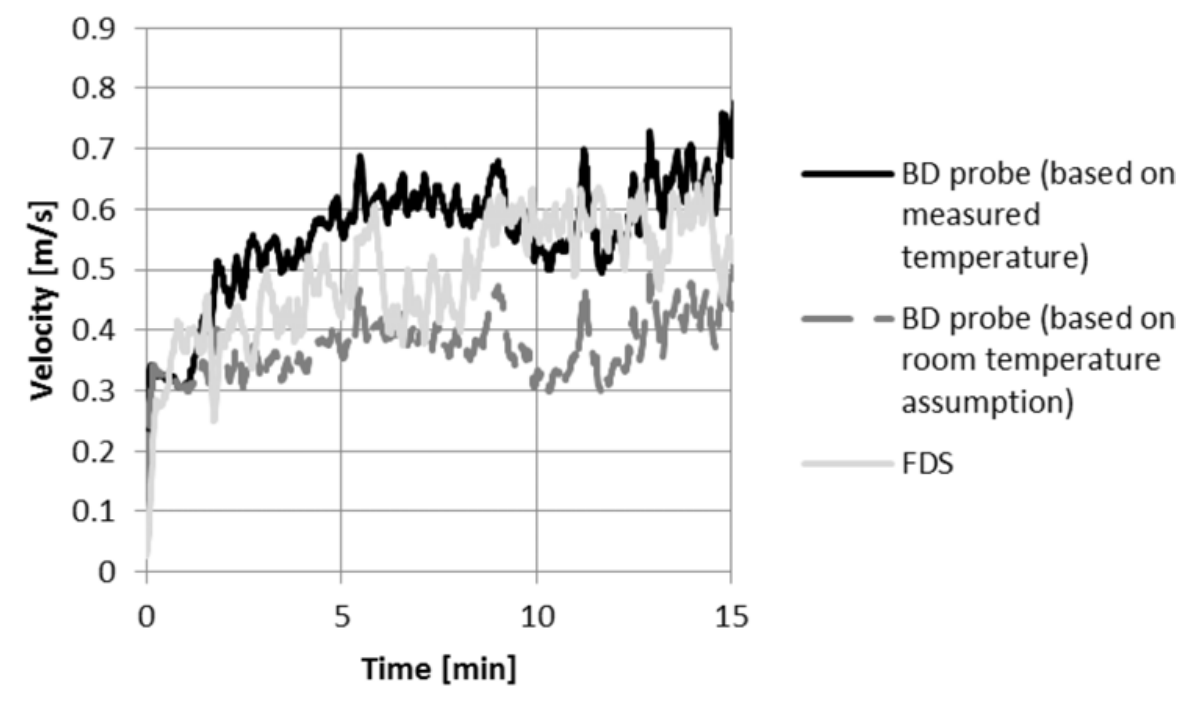

Figure 6. Velocities into the fire room in the air-intake behind the fire tray from test A.

The bi-directional probe measures the pressure differences in the gas in the direction of the flow. The measurement has to be compensated for the density change with temperature and the local Reynolds number according to the relationship,

$$
v=\frac{1}{k(\operatorname{Re})} \sqrt{\frac{2 \Delta p T}{\rho_{0} T_{0}}}[\mathrm{~m} / \mathrm{s}] .
$$

Here $\mathrm{k}(\mathrm{Re})$ is a correction coefficient found in Olsson [8], $\mathrm{T}$ is the gas temperature, $\Delta \mathrm{p}$ is the pressure difference, $\rho_{0}$ is the ambient density and $\mathrm{T}_{0}$ is the ambient temperature. The correction coefficient is a measured quantity and is approximately constant for a large range of Reynolds numbers (Re). Roughly, in the range $\mathrm{Re}=400-3800$ a correction coefficient of $\mathrm{k}(\mathrm{Re}) \approx 0.9$ is found. Using the relation above, the velocities presented in, Figure 6 with experimental data from test A, and Figure 8 with experimental test data from test B, are found.

In Figure 6 the velocity upwards into the fire room is estimated, the velocities using the thermocouple temperature and the room temperature in equation (1) are shown. In computing the gas velocity the gas temperature is needed, however we have used the temperature measured by a $1 \mathrm{~mm}$ thermocouple which includes an error from radiation. In the air-intake behind the fire tray cold air is entering while there is a strong radiative exchange with the surroundings above indicating that the actual gas temperature is difficult to measure. Hence in Figure 6 we show also the results from velocities calculated from a room temperature assumption. When analyzing the FDS simulation it is found that the gas temperature is close to room temperature whereas the thermocouple yield higher temperatures see Figure 7 . Note that the thermocouples used in FDS have significantly higher temperatures. 


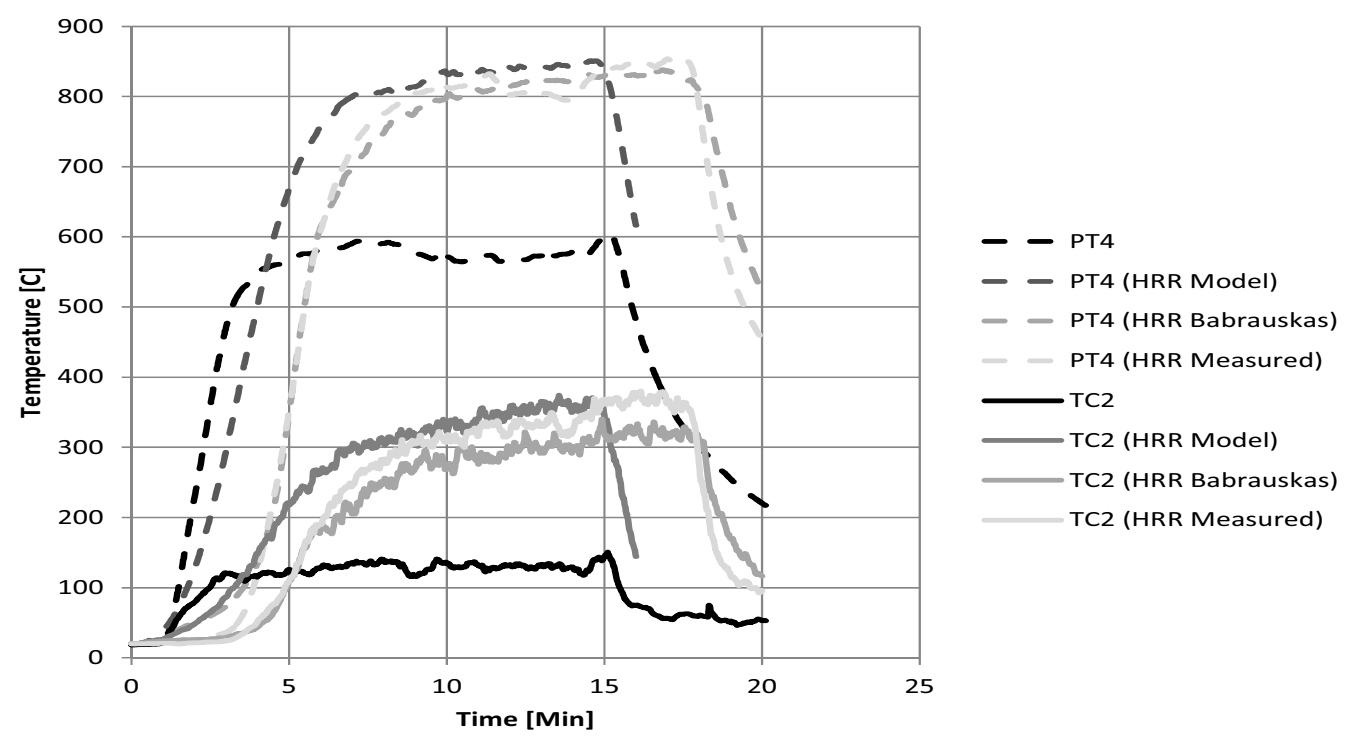

Figure 7. The plate thermometer and the thermocouple temperatures in the air-intake behind the fire tray from test A.

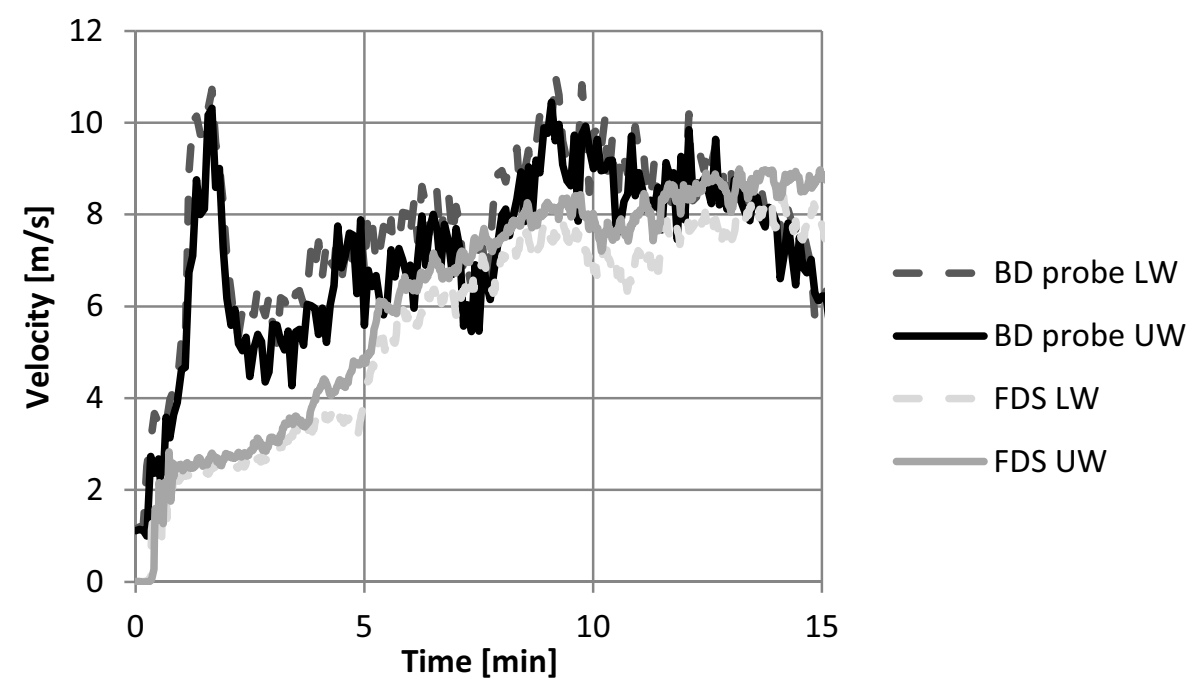

Figure 8. Comparison of the gas velocity along the façade between the measured data and the simulated velocities using Babrauskas HRR at the lower window (LW) and the upper window (UW) (from test B).

Furthermore, in Figure 7 the resulting temperatures, measured by plate thermometers and thermocouples, comparing the different heat release rates defined in Figure 4 are displayed. The corresponding temperatures found in the FDS simulations are considerable higher in all cases, presumably due to the fact that local effects coming from the evaporation of the heptane liquid and combustion, due to the design of the fire tray, are important and are not captured when a heat release rate is given as an input to the simulation.

In Figure 8, the gas velocities along the façade are shown measured by the bi-directional probes in the lower and upper window compared to the results found by using the numerical model with the 


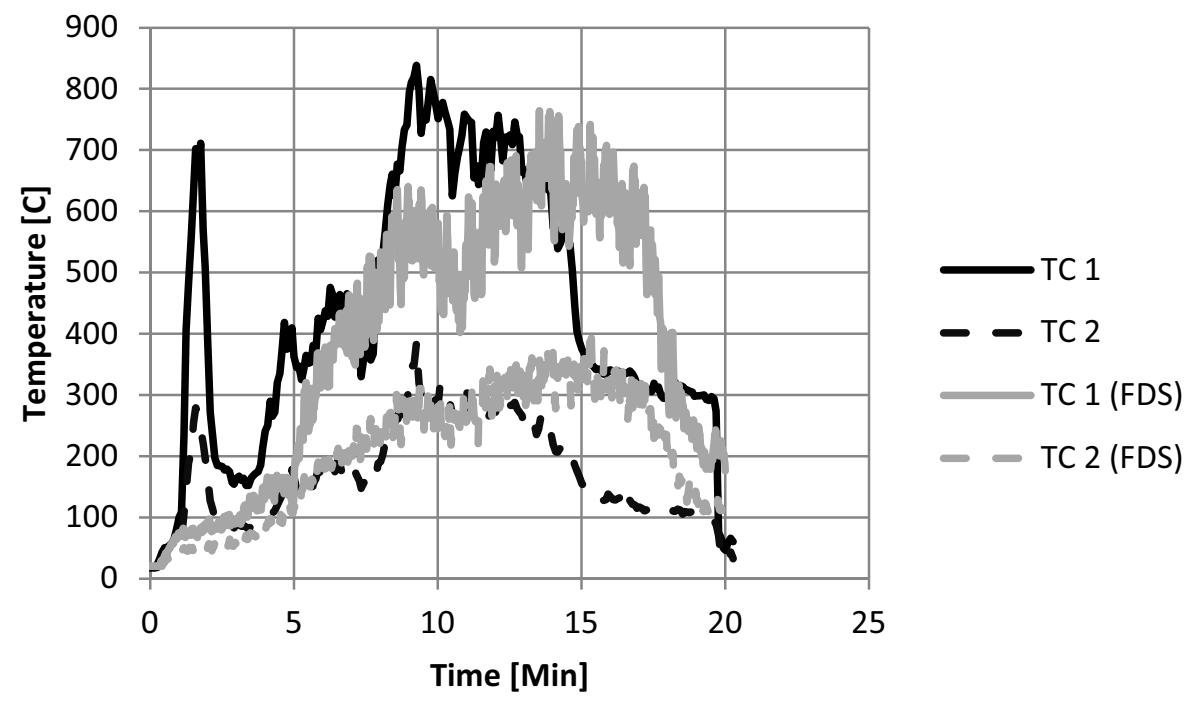

Figure 9. The measured temperatures compared to the simulated data using Babrauskas HRR in the lower window (TC 1) and the upper window (TC2) from test B.

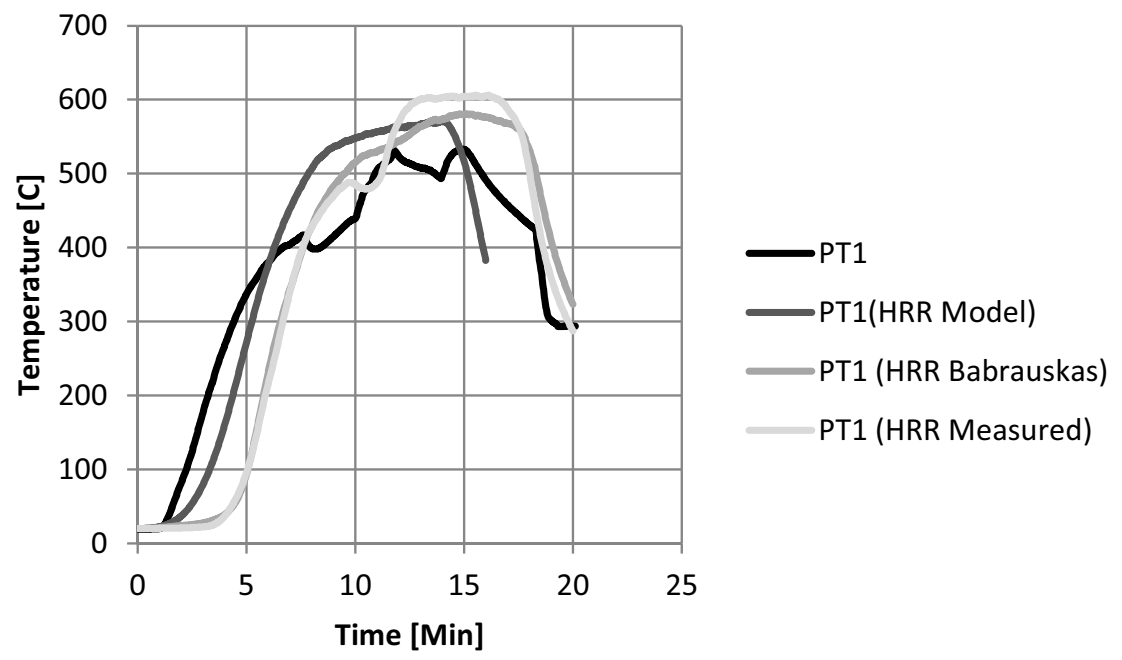

Figure 10. The plate thermometer temperatures in front of the fire room using different HRR curves in the simulation compared to the measured data from test A. (PT placed on the floor $50 \mathrm{~cm}$ from the test rig and $50 \mathrm{~cm}$ to the left of the symmetry line of the test rig. Measurement direction upwards).

Babrauskas HRR. Short after the start of the test a rapid fire growth is observed, resulting in peaks in the gas velocities as well as the gas temperatures. The peak is followed by a colder period and then a regular growth to the maximum fire intensity after 8 minutes. The total energy in the peak is not significant enough to change the test results. We find a relatively good correspondence between the estimated measured gas velocities and the simulation data except during the peak in the beginning of the test. It is also observed that the temperatures measured by the $1 \mathrm{~mm}$ thermocouples are close to the simulation results and also the actual gas temperatures in the simulation. 


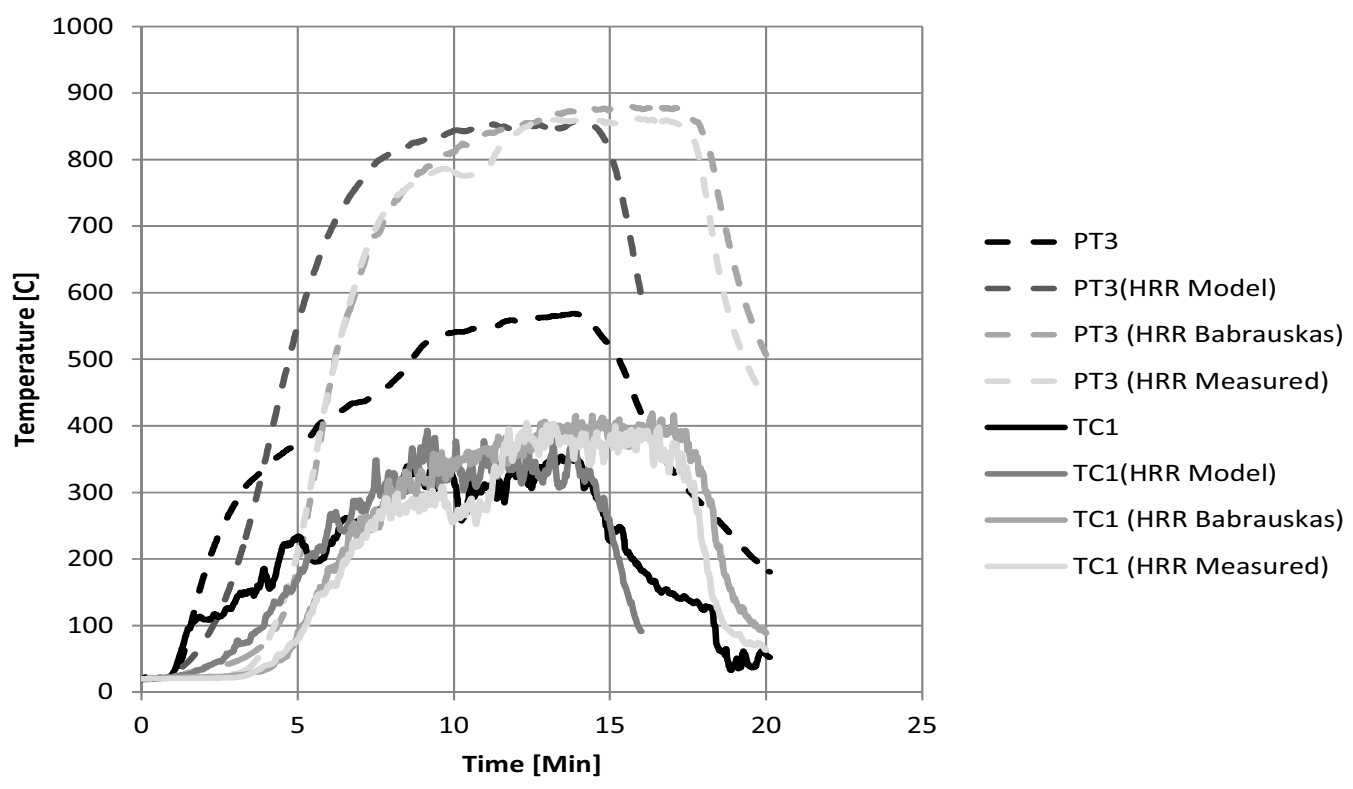

Figure 11. The plate thermometer and thermocouples in the lower right corner of the fire room from test A. (TC in the right lower corner at the entrance of the burning chamber $20 \mathrm{~cm}$ from the floor and $20 \mathrm{~cm}$ from the wall. $P T$ in the right lower corner at the entrance of the burning chamber $10 \mathrm{~cm}$ from the floor and $10 \mathrm{~cm}$ from the wall. Measurement direction inwards).

In general, the upward components of the gas velocities found in the simulations have good correspondence to the experimental values if not considering the initial peak. Although we did not account for the flange at the edge of the windows in the model the results from the simulations could capture the flow speeds and the gas temperatures rather well on the results presented in Figure 8.

\section{ELABORATION ON THE EFFECTS OF HRR IN THE SIMULATION}

Here we revisit the old data from test A where we compared the experimental data using the model heat release rates. In this new comparison we use the heat release rates defined by Babrauskas [6] and a measured heat release rate with an inert façade, see figure 4 for the details on the heat release rates.

In Figure 10, the temperatures measured by a plate thermometer placed on the floor in front of the fire room are shown compared the simulation results using the model HRR, Babrauskas HRR and the measured HRR. The dent in the measured temperature curve is due to parts of the façade falling down on the plate thermometer. It is found that the maximum temperature is well reproduced in the simulations however a lag in the temperature increase is found.

In Figure 11, measurements with a plate thermometer and a thermocouple in the lower right corner of the fire room are presented. It is found that the values of the temperature measured by the thermocouple are well represented by the simulations however the same correspondence is not found for the plate thermometer. We note that there is a lag in all simulated data compared to the measurements. Similar behaviour is found in results presented in Figures 7 and 10 and seems to be systematic. Here it is likely that the details of the combustion are affected by geometry of the fire tray, while giving the measured heat release rate, the rate of combustion at different locations is not reproduced. Neglecting the full combustion dynamics is a plausible reason for these discrepancies. It is also interesting to mention that the flame suppressing lattice placed over the fire tray reduces the combustion rate compared to what a 


\section{MATEC Web of Conferences}

pool fire would yield. This is also found in numerical experiments as a pool fire model would give much too high burning rate.

\section{SUMMARY}

A study on comparisons between simulation results and two experiments in the SP Fire 105 test rig [4] elaborating on previous results presented in references [1,2] have been performed. In the FDS5 simulations [5] a design fire based on observations of the fire intensity during the test is used in tandem with measured heat release rate (HRR) data of reference [6] and a measured HRR using an inert façade. The used model HRR is validated by previous measurements of HRR with the same test setup and the knowledge of the total fire load of 60 litres of heptane. The two tests were performed using two different wall claddings (material data given in Table 2) where one of them was inert.

Although, during the second test a peak in HRR was observed in the early stages of the test this dissipated and a shorter colder period commenced, followed by the full force of the fire after 8-16 minutes. Since the difficulties of the geometry, i.e. the flame suppressing lattice consisting of a perforated steel sheet with pipes of $25 \mathrm{~mm}$ diameter placed in the fire tray, the numerical model could not resolve the flows close to the fire tray. Note that good information on the actual HRR in the test is needed for reproducing detailed fire dynamics of the test rig, in particular where a pulsation in the fire intensity is obtained during test. Despite this we note that the total amount of energy released during such a peak is rather small compared to the total energy and would not likely influence the end result in a testing procedure.

In general, good agreement between the experimental data and the numerical model was found where the measured HRR was used as an input in the simulations. In most cases, the discrepancies found between the measured and simulated date occurred close to the fire source. More specifically, we have compared the gas velocities in the air-intake and flow velocity along the façade measured by bidirectional probes and the velocities found in the numerical model. It is noted that the gas temperature is needed to compute the gas velocity however the actual gas temperature may be difficult to measure due to radiation errors. The gas velocity in the air-intake behind the fire tray found using the BD-probes is well reproduced by simulations using a slightly lower gas temperature as indicated by the simulations. The velocity of the hot gases along the façade is rather well reproduced by the simulations although some deviations were found. A possible source of this deviation is that the flanges at the lower edges of the fictitious windows were not included in the numerical model.

Revisiting old data using a set of different HRRs the same correspondence was not found for the plate thermometer in the lower right corner of the entrance of the burning chamber and for the plate thermometer and thermocouple in the air-intake. In these cases the numerical model gave substantially higher temperatures. We note that there is consistently a time lag between the simulated results and the measured temperatures. Reasons for this are unclear however it is possibly a consequence of the shape of the flame suppressing lattice in the fire tray that lead to different local combustion effects compared to burning from a liquid surface not reproduced by using a heat release rate as an input to the simulation. It is interesting to note that a pool fire model not impeded by the flame suppressing lattice have a much faster burning rate and more local combustion effects.

The authors are grateful to the SP technicians for their help during instrumentation of the façade experiment and Michael Rahm for sharing the experimentally determined heat release rate.

\section{References}

[1] Jansson, R., Anderson, J., Experimental and numerical investigation of fire dynamics in a façade test rig, Proceedings of Fire Computer Modeling, Santander, Spain, 18-19 $9^{\text {th }}$ October 2012, p. 247. 
[2] Anderson, J., Jansson, R., Fire Dynamics in Façade Fire Tests: Measurement and Modeling, Accepted to Interflam 2013.

[3] Hildebrand, C., Façade Fire Testing, report CIB 14 Workshop, Institute fur Baustoffe, Leipzig, April 1988.

[4] SP FIRE 105, - Method for fire testing of façade materials, Dnr 171-79-360 Department of Fire Technology, Swedish National Testing and Research Institute.

[5] McGrattan, K., McDermott, R. Hostikka, S. Floyd, J., Fire Dynamics Simulator (Version 5) - user's guide. NIST Special Publication 2010.

[6] Babrauskas, V., Facade Fire Tests: Towards an International Test Standard, Fire Technology 32, 219-230 (1996).

[7] Mc Caffrey, B. J., Heskestad, G., Brief communications: A robust bidirectional low-velocity probe for flame and fire application, Combustion and Flame 26 pp 125-127 (1976)

[8] Olsson, S., Brandforsk project 020-82-1, SP Report 1988:34 (in Swedish)

[9] Sundström, B., Wickström, U., "Fire: Full Scale Tests Calibration of Test Room - Part 1", Technical Report SP - RAPP 1981:48, Borås, Sweden, 1981. 